\title{
TRABAJO SOCIAL Y JUSTICIA SOCIAL EN TIEMPOS DE TRANSICIÓN*
}

\section{SOCIAL WORK AND SOCIAL JUSTICE IN TIMES OF TRANSITION}

\author{
María Rocío Cifuentes-Patiño** \\ Sandra Yaneth Vallejo-Gonzálezz**
}

\begin{abstract}
La tradición está en un constante cambio. "Adherirse a ella" es la formulación de una experiencia en virtud de la cual nuestros planes y deseos se adelantan siempre a la realidad, sin supeditarse a ella, por decirlo así. Se trata pues de mediar entre la anticipación de lo deseable y las posibilidades de lo factible, entre los meros deseos y el verdadero querer; esto es se trata de integrar las anticipaciones en el material de la
\end{abstract} realidad.

(Gadamer, 2004, p. 259)

\section{Resumen}

Objetivo. Motivar la reflexión de profesionales de ciencias sociales especialmente trabajadores sociales, con respecto a los retos del proceso de construcción de paz, con justicia social. Metodología. Para elaborarlo se consultó: 1) la investigación que en el tema se ha adelantado en el grupo de investigación Cedat. 2) Las experiencias de proyección social del centro Cedat. 3) Literatura sobre el tema de justicia social y paz. Resultado. En el texto se derivan responsabilidades y retos, presentes y futuros para trabajo social, con relación al proceso de transición hacia la construcción de paz con justicia social. Conclusión. El trabajo social debe: 1) Involucrar una concepción plural de justicia social (restaurativa, redistributiva y justicia como reconocimiento). 2) Considerar la ciudadanía y la participación social como: campos de encuentro inter y transdisciplinar; objetos de acción, disputa política e investigación. 3) Gestar compromiso colectivo con la transición.

Palabras clave: transición, construcción de paz, justicia social, reconocimiento, distribución y trabajo social.

\footnotetext{
* El artículo se deriva de la conferencia central, presentada en la "XXIV Jornada de Exposición de Proyectos de Investigación y Práctica: Trabajo Social para la Construcción de Paz”, en el marco de la conmemoración de los 50 años del Programa de Trabajo Social de la Universidad de La Salle. Bogotá, noviembre 2 y 3 de 2017.

** Universidad de Caldas. Manizales, Colombia. E-mail: maria.cifuentes@ucaldas.edu.co - (D orcid.org/0000-0002-3899-0017. Google Scholar

**** Universidad de Caldas. Manizales, Colombia. E-mail: sandra.vallejo@ucaldas.edu.co -

(D) orcid.org/0000-0002-9564-3134. Google Scholar
} 


\begin{abstract}
Objective. To motivate the reflection of social science professionals, especially social workers, regarding the challenges of the peace building process with social justice. Methodology. In order to elaborate this reflection, it was necessary to consult: 1) the research carried out by the Cedat research group in this area; 2) the social projection experiences of the Cedat center; and 3) literature on the area of social justice and peace. Results. Responsibilities and challenges, present and future, for social work in relation to the process of transition towards the construction of peace with social justice are derived from the text. Conclusion. Social work must: 1) involve a plural conception of social justice (restorative, redistributive and justice as recognition); 2) consider citizenship and social participation as inter and transdisciplinary meeting point, object of action, political dispute and investigation; and 3) develop collective commitment with the transition.
\end{abstract}

Key words: transition process, peace building, social justice, restorative justice, redistribution, social work.

\title{
Introducción
}

Es compleja la situación que afronta hoy el país, polarizado ante un proceso de construcción de paz, iniciado con los polémicos acuerdos suscritos entre el gobierno colombiano y uno de los actores armados de la insurgencia, las FARC/EP. La emergencia de disidencias y las enormes dificultades y dilaciones en la implementación de lo acordado configuran una amenaza permanente para la consolidación de este proceso. De otra parte, los diálogos con el ELN no han logrado consolidarse, tanto por las condiciones mismas de la negociación como por los resultados de la implementación del acuerdo con las FARC/EP y por los actos bélicos que siguen siendo noticia de primer orden en el país. Toda esta situación incide en la actual contienda política electoral. Sin embargo, la construcción de paz no es un tema coyuntural ni se reduce, como tanto se repite, a los acuerdos entre actores armados. Se trata de un derecho que ha de realizarse con la convergencia de la sociedad toda y en cuya realización cabe responsabilizar tanto al Estado, como a los excombatientes, a la institucionalidad, a la sociedad civil, a la academia y aún a las propias víctimas.

A pesar de las complejidades y las amenazas que enfrenta en Colombia el proceso de construcción de paz, iniciado con la desmovilización de la guerrilla más vieja del continente y quizás por ello con este artículo pretendemos invitar a la corresponsabilidad de los profesionales de las ciencias sociales, especialmente trabajadores sociales, para que la transición que se anuncia en el país se haga realidad y se consolide más allá de la dejación de armas de uno u otro actor de la guerra. 
Trabajo social y justicia social en tiempos de transición

La reflexión en torno al papel del trabajo social colombiano en un proceso tan complejo, en el que la construcción de paz se debate entre incertidumbres y amenazas, la proponemos desde el eje de la justicia social, para ello la argumentación se desenvuelve en perspectiva histórica y conceptual.

Inicialmente, leemos en el surgimiento y en la trayectoria del trabajo social en Colombia, el compromiso con el tema de la justicia social. Seguidamente, reconocemos la relación entre la construcción de paz y las concepciones de justicia. Con base en los dos argumentos previos y desde nuestra lectura de la coyuntura colombiana actual, proponemos una concepción plural de justicia social, que involucra justicia restaurativa, justicia redistributiva y justicia como reconocimiento. Desde esta concepción hilvanamos los retos del trabajo social en relación con el complejo e incierto proceso de transición hacia una sociedad que tramite sus conflictos a través de la política y no de la violencia armada. En este contexto le otorgamos lugar de significativa importancia a la ciudadanía y a la participación social como campos de encuentro inter y transdisciplinar; objetos de acción profesional, disputa política e investigación.

\section{Discusión}

Para examinar el tema anunciado en el título "Trabajo social y justicia social en tiempos de transición”, nos acercaremos, en perspectiva histórica, a los orígenes del trabajo social en Colombia, para rastrear desde estos la imbricación con el tema de la justicia social. Con este punto de partida nos acercaremos al tema de la justicia en tiempos de transición, para establecer como esta, aunque ha de involucrar la justicia transicional, debe trascenderla hacia una perspectiva plural de justicia social. Se cierra este acápite conceptualizando la noción de justicia social y argumentando esta como condición para la construcción de paz.

\section{Visitando brevemente los orígenes del trabajo social, para pensar el presente y proyectar el futuro}

En Colombia el trabajo social ${ }^{1}$ surgió en medio de un contexto económico, político y social convulsionado que caracterizó el país en la primera mitad y en el tránsito a la segunda del siglo previo. Un contexto de profundas desigualdades sociales y de injusticias que no sólo implicaban las clases sociales, sino que trascendían a otras dimensiones de la vida social, tales como las relacionadas con los derechos civiles y políticos de las mujeres. Un contexto en el que la religión católica ocupó un lugar protagónico, más allá de lo propiamente religioso y de las decisiones privadas de los sujetos en torno a asumir o no un credo y cuál asumir.

\footnotetext{
${ }^{1}$ Inicialmente, servicio social,
} 
En la primera mitad del siglo XX, los efectos de los nacientes procesos de urbanización e industrialización -la pobreza con sus múltiples manifestaciones, la situación de los obreros de la época y de sus familias--, emergían como problemas sociales de primer orden, que demandaban respuestas gubernamentales.

La gran depresión económica iniciada en 1929 y el fin de casi medio siglo de gobiernos conservadores [...] plantearon el reto de conjurar los efectos de la crisis [...] en el primer gobierno de Alfonso López Pumarejo (1934-1938) [...] reformas en varios frentes: constitucional, agrario, tributario, educativo, laboral, judicial y de relaciones exteriores [...] libertad de conciencia y de cultos [...] derecho a la huelga, se elevaron los recaudos del Estado [...] mecanismos de protección a la maternidad [...] la modernización [...] de la educación [...] medidas que se insertaron en nacientes procesos económicos de tipo capitalista y las relaciones sociales correspondientes. (Cifuentes y Gartner, 2006, p. 12)

Esa convulsionada sociedad colombiana de la primera mitad del siglo anterior dio origen a profundas transformaciones en todos los campos, en medio de complejas luchas por el modelo estatal, protagonizadas principalmente por liberales y conservadores. A los cambios que vivía el país en la época, Uribe (2001) los define como una crisis de crecimiento
la agudización de los conflictos, la polarización de fuerzas, los desajustes sociales, la transformación de mentalidades, de actitudes y de comportamientos; crisis que [...] vienen acompañadas de violencia y de confrontaciones agudas y también del surgimiento de nuevas alternativas políticas $^{2}$. (p. 61)

Es en ese país agitado, atravesado por múltiples violencias y, al mismo tiempo, por vientos de cambio, en el que se gestó la primera escuela de servicio social con una orientación correspondiente a los retos propios de la época. Con respecto a los propósitos de la naciente profesión en el país, decía María Carulla en entrevista con el diario ElTiempo, el 22 de octubre de 19373: "Trabajar por levantar el nivel moral, cultural, económico e higiénico y prestar apoyo necesario para que aquellos que son menesterosos, puedan usufructuar de las instituciones que la sociedad tiene organizadas con el fin de conseguir una mayor Justicia Social"4. (ElTiempo como se citó en Cifuentes y Gartner, 2003, p. 36).

Además de la atención a los problemas gestados en la sociedad de la época, como fruto de las complejas condiciones de injusticia económica, el surgimiento de la escuela de servicio

\footnotetext{
${ }^{2}$ El subrayado es nuestro.

${ }^{3} \mathrm{~A}$ un año de creada la escuela, pero, a sólo 7 meses de haber iniciado labores.

${ }^{4}$ El subrayado es nuestro.
} 
Trabajo social y justicia social en tiempos de transición

social responde a otro tipo de tensiones generadas en persistentes injusticias de carácter político y cultural, enraizadas no sólo en las jerarquías de clase social, sino en la estructura patriarcal de la sociedad. Ello es, las limitaciones para la inserción de las mujeres en la vida económica, la participación social y política y el ingreso a la educación superior. Con respecto al último asunto, decía la primera estudiante graduada de la escuela: "No era fácil elevar a nivel universitario a una mujer para quien no existía el bachillerato” (María Carrizosa de Umaña como se citó en Cifuentes y Gartner, 2003, p. 30).

Así, aunque con un discurso fuertemente influenciado por los preceptos de la iglesia católica y sin entrar en frontal contradicción con las atribuciones tradicionales de género, esta escuela abre compuertas a procesos de transformación de los roles de las mujeres en la conservadora sociedad colombiana. Abrir una escuela de nivel universitario para mujeres ${ }^{5}$, que logra fuerte inserción institucional y social a través de las investigaciones y de las prácticas de las estudiantes y del ingreso al mundo laboral de las egresadas, fue un significativo desafío para la época.

En esta dinámica, cambiante y confusa realidad surgió la primera escuela,
en cuya propuesta fundacional [...] se reflejaron las tensiones políticas
propias de la época, en tanto se imbricaron nociones del proyecto
político conservador (el fundamento religioso y ciertas legitimaciones
éticas y culturales de corte tradicionalista), con preceptos del proyecto
modernizador liberal, fundamentado en los valores de ciudadanía,
derechos civiles, libertades y desarrollo económico [...] sustanciales
cambios en la dinámica y en el ordenamiento social (en las formas de
tramitación de las inconformidades y en la organización social) y en
el que la legitimidad de los partidos políticos empezaba a agrietarse.
(Cifuentes y Gartner, 2006, p. 13)

Esta breve visita a los orígenes del trabajo social en el país apenas abre la puerta a la tradición, no para sobredimensionarla, sino para comprendernos en su devenir y para proyectarnos en conversación con nuestro acontecer histórico. Al decir de Gadamer (2005),

el contenido de la tradición entra en juego y se despliega en posibilidades de sentido y resonancia siempre nuevas y siempre ampliadas de nuevo por su nuevo receptor. Cuando la tradición vuelve a hablar, emerge algo que es desde entonces, y que antes no era. (p. 553)

\footnotetext{
${ }^{5}$ En esta primera escuela estudiaban mujeres de clase alta que eran quienes podían acceder a ella, no sólo por razones económicas, sino también por la valoración que en sus contextos se podía dar a la educación de las mujeres, más allá de la preparación para lo exclusivamente doméstico. En estos 81 años de historia el trabajo social se ha popularizado, a ello ha contribuido, de una parte, su tránsito a universidades públicas y de otra la ampliación de la oferta de formación universitaria para mujeres que ha marcado la posibilidad, principalmente para quienes se ubican en altos sectores socioeconómicos, de seleccionar entre una amplia gama de opciones profesionales y disciplinares.
} 
Se trata, por tanto, de preguntarnos en clave histórica al tenor de la realidad actual, sobre nuestra responsabilidad presente y futura. Se trata de interpelarnos frente a esa realidad que, tanto se parece y tan diferente es de aquella que posibilitó el surgimiento de la profesión en el país; esa que nos asoma complejos retos que hemos de encarar intergeneracionalmente hoy y que seguirán asumiendo las nuevas generaciones de trabajadores sociales en su ejercicio profesional de mañana.

Así, de la mano de Gadamer, daremos un salto de ocho décadas, para referirnos al trabajo social colombiano en el contexto de los retos con relación al proceso de construcción de paz. Lo anterior desde una mirada de la justicia social.

\section{Justicia en tiempos de transición}

Las luchas por el reconocimiento tienen lugar en un mundo de desigualdades materiales exacerbadas: en cuanto a la renta y la propiedad, en el acceso al trabajo asalariado, la educación, la asistencia sanitaria y el tiempo de ocio [...], en el consumo de calorías y la exposición a la toxicidad medioambiental [...] en las expectativas de vida y las tasas de enfermedad y mortalidad. La desigualdad material va en aumento en la mayoría de los países [...] está aumentando globalmente, y de forma más acentuada de acuerdo con la línea que divide el norte del sur. (Fraser, 1997, p.18)

[...] el modelo occidental [...] extiende su influencia por todos los continentes, se percibe como un modelo en crisis, incapaz de resolver los problemas de la pobreza [...], incapaz de acometer graves problemas como el paro, la delincuencia, la droga y muchos otros. (Maalouf, 2002, p. 97)

Cuando como trabajadoras sociales que participamos de la formación de las nuevas generaciones de profesionales nos enfrentamos a la reflexión acerca de los retos que el momento histórico nos está planteando, nos vemos compelidas a buscar en la historia del trabajo social claves para esclarecer nuestra responsabilidad social, en tanto profesión que se interpela desde la justicia como principio, como fin, como enfoque, como campo de investigación y de acción profesional. En un país como el nuestro en el que estamos frente a la compleja tarea de transitar de una larga guerra, a dirimir los conflictos sociales por la vía de la política, se impone pensar en clave de justicia social. Esta, necesariamente, involucra reparación y garantía de derechos a las víctimas; reconocimiento de responsabilidades, esclarecimiento de la verdad, quizás, sería mejor decir, parafraseando a Hilb (s.f), la construcción de una verdad más compleja, aceptación de responsabilidades y de las consecuencias jurídicas que de ello se derivan, según un complejo balance entre respeto al ordenamiento jurídico y preeminencia del derecho a la paz. Todo ello es necesario mas no suficiente para el tránsito que como sociedad debemos dar. 
Trabajo social y justicia social en tiempos de transición

Este tránsito, como se repite a menudo, con el riesgo de convertirse en cliché, debe fundamentarse en una paz con justicia social. Más allá del debate sobre la aplicación de la ley a los culpables de crímenes de guerra, esta noción nos obliga a pensar en las injusticias que permean la vida social hoy, que no distan mucho de las que marcaron el origen del conflicto armado y, más atrás, el surgimiento de la primera escuela de servicio social. Estas se erigen como los mayores obstáculos para la construcción de paz, obstáculos aún más poderosos que los detractores del actual proceso.

Hoy, como hace ocho décadas, la desigualdad y las injusticias sociales permanecen sin resolver, tal vez sería mejor decir que se han acentuado y se han complejizado. Basta con sólo echar una mirada a algunos temas tan sensibles a la vida social como la salud, la educación, el empleo, la situación del campo y los problemas ambientales, para entender la magnitud de la crisis por la que estamos atravesando. Las violencias, más allá de los territorios de conflicto, se entronizaron en la vida social; la corrupción corroe la vida institucional y política y da paso a una crisis moral de devastadoras consecuencias sociales; la desconfianza, el miedo y una compleja mezcla de polarización e indiferencia campean en la vida social erigiéndose como obstáculos monumentales a la participación ciudadana y al ejercicio de la política como medio de construcción colectiva de la vida social (uno sólo de los múltiples ejemplos que tenemos a disposición en la vida diaria es suficiente evidencia de ello, el asesinato de líderes sociales que significa, además de la invaluable pérdida de vidas, el menoscabo de las organizaciones). El país se debate en una encrucijada política en la que se asoman vientos encontrados de cambio y de continuidad, entre los cuales, el tema de los acuerdos gobierno-insurgencias (el logrado con las FARC/EP y el que está en proceso con el ELN) se erige como lugar de enfrentamiento entre detractores y defensores. En este caldeado clima político-social, estamos ad portas de una contienda electoral compleja y tenemos la tarea de trascender del tema de los acuerdos (blindando estos), a la construcción de lo que se ha dado en llamar "paz con justicia social”.

Cuando decimos justicia en este momento histórico, es obligado el tema en relación con los acuerdos. En esta perspectiva, en un intento arriesgado de síntesis de lo heterogéneo, podemos identificar posturas convertidas en "caballito de batalla" en la escena pública, que confunden al ciudadano corriente y tienden a aparecer como diferencias inconmensurables en el debate político, a saber:

- Una posición crítica del acuerdo entre el gobierno y las FARC/EP, que señala a este de sustentar la impunidad. Se trata de una lógica de justicia retributiva (penal), circunscrita a la aplicación de la ley y, en consecuencia, a la asignación y la ejecución de penas a los culpables de crímenes, en el marco y a causa del conflicto armado, de manera proporcional a los delitos cometidos. Esta se reflejó, de alguna manera, en las tensiones y en los debates generados en el tránsito por el Congreso de la República del proyecto de acto legislativo que da vida a la Jurisdicción Especial para la Paz -JEP- y los cambios efectuados al mismo. 
Otra posición, en la línea de administración de justicia, que toma distancia de la primera, en cuanto admite como necesaria la flexibilización, para dar lugar a la salida negociada al conflicto, a través de una concepción de justicia transicional. Esta en el país se ha ido definiendo al tenor de los avatares de cada uno de los procesos de negociación dados entre el gobierno y distintos actores del conflicto armado. En relación con ella, aparece la noción de justicia restaurativa como un modelo que trasciende lo exclusivamente jurídico. Esta última, de una parte, toma en consideración los derechos de las víctimas; la reparación a ellas, tanto material como simbólica y, de otra parte, abona el camino a la reconciliación con base en la reconstrucción de la verdad de los hechos de guerra, los daños causados y la aceptación de las responsabilidades con respecto a ellos; la realización de acciones reparadoras a sujetos y a colectivos por parte de los responsables y las garantías de no repetición. Es en este marco en el que se ubica lo establecido en la JEP, que involucra mecanismos, judiciales y extrajudiciales. La justicia restaurativa es una perspectiva, necesaria pero no suficiente, para abonar el camino a la reconciliación y la paz. Esta aproximación es necesaria por cuanto es indispensable que las víctimas estén en el centro tanto del acuerdo como de su implementación, lo que se ha visto afectado con los cambios producidos en relación con lo acordado en el ejercicio legislativo para la implementación. Aunque por efecto del acuerdo de La Habana, el número de víctimas no crece en la misma proporción que en años anteriores, el número de estas no ha parado de aumentar. A pesar del subregistro, las cifras oficiales señalan que a $1^{\circ}$ de noviembre de este año hay 8.581.339 víctimas, incluidas en el Registro Único - RUV-. Este complejo y extenso conflicto armado - en el tiempo y en la geografía nacional- en buena medida, se disputó y, aún sigue disputándose, sobre el cuerpo de la sociedad civil, lo que deja una estela de daños que se erigen como retos a la construcción de paz estable y duradera.

Al decir atrás que la justicia restaurativa es "necesaria pero no suficiente", estamos hablando de que "la paz con justicia social", hace alusión no sólo al castigo a los responsables de crímenes de guerra y a la reparación posible (es indudable que hay daños irreparables) e indispensable a las múltiples víctimas, sobrevivientes del conflicto armado. Pensar la justicia, como 'social', implica reconocer la desigualdad social, la exclusión, la opresión, la dominación, las violencias, las jerarquías de poder en las que se incardinan todas esas injusticias (Foucault, 1992). En fin, todo aquello que sirvió de caldo de cultivo para la emergencia del conflicto armado y que ha posibilitado que este se extienda por décadas. Ello es, injusticias que involucran no sólo las privaciones o inequidades en el plano de lo material, sino también en la esfera de lo simbólico y en el ejercicio del poder. Estas injusticias, como decíamos al comienzo de este acápite, no sólo no se han resuelto, sino que se han agudizado y complejizado en el país. De esta manera, "la paz con justicia social" involucra condiciones como el enfoque territorial, el enfoque diferencial, el enfoque de género, la garantía de derechos la participación política. Ello, con respecto a los acuerdos de La Habana, ha sido objeto de férrea oposición por ciertos sectores del país que leen en esta perspectiva una amenaza. Sin embargo, dado el panorama 
de injusticias, tanto derivadas de la guerra como de la estructura social, transitar el azaroso camino de la construcción de paz supone que esta hunda sus raíces donde se han arraigado las injusticias para socavarlas, es decir, que involucre la estructura económica, social, política y cultural del país. Se trata de una paz sustentada en una perspectiva plural de justicia social, pues, como lo propone Waltzer (2001), "Los principios de la justicia son en sí mismos plurales" (p. 113).

\section{Justicia social, condición para la paz}

Para sustentar en el acápite final la responsabilidad de trabajo social con la investigación y la acción en la construcción de paz fundamentada en una noción de justicia social, que involucra pero trasciende el enfoque de justicia transicional, partiremos de una breve ubicación teórica del tema; en conversación con desarrollos actuales sobre justicia social, nos referiremos a dos tipos de justicia que enfrentan a teóricos contemporáneos (comunitaristas, multiculturalistas, liberales, socialistas), trenzados en agudos debates académicos acerca del tema. De los muchos que han participado en tales debates nos apoyaremos, fundamentalmente, en lo argumentado por Iris Marion Young (1990, 1998, 2000, 2003), Fraser (1997, 1998, 2000, 2003) y Fraser y Axel Honneth (2006). Estos autores coinciden, a pesar de sus enconadas diferencias teóricas, en reconocer que hay injusticias originadas en la estructura económica de la sociedad y otras referidas a la estructura político-cultural de la misma. Unas y otras, demandan respuestas que tienden a interferirse entre sí, pero que son ambas indispensables cuando el propósito es construir "paz con justicia social". Las salidas a las injusticias socioeconómicas reclaman eliminar las diferencias, se trata de justicia redistributiva, orientada a avanzar en dirección a la igualdad. Las salidas a las injusticias culturales implican afirmar las diferencias, portadas por colectivos tradicionalmente estigmatizados y excluidos en las lógicas de la cultura dominante, por ejemplo, aquellos referidos a la raza, el género y la étnia; se trata de justicia como reconocimiento. Más allá de lo que pareciera una visión atrapada en un dilema dicotómico, redistribución- reconocimiento, los autores, cada uno por una vía diferente, buscan encontrar salidas abarcadoras a las injusticias sociales en las cuales leemos claves, en relación con el reto que nos convoca como trabajadores sociales y como ciudadanos colombianos. Young (2000) propone conceptualizar las injusticias en términos de dominación y opresión ${ }^{6}$, no reducir sus soluciones a lo meramente distributivo, ni extender la distribución a asuntos no materiales. Plantea que se deben reconocer las diferencias en vez de oprimirlas, ampliar y democratizar la noción de lo público, involucrar la ética del cuidado y desmantelar las jerarquías. Argumenta la necesidad de construir estructuras sociales e instituciones participativas que, de manera democrática, convoquen y favorezcan la expresión de voces diversas. Fraser (2001), por su parte, propone lo que ella denomina una opción transformativa en términos tanto económicos como culturales, que involucre medidas de reconocimiento y de redistribución

\footnotetext{
${ }^{6} \mathrm{Al}$ respecto propone una categorización que es, simultáneamente, plural y limitada.
} 
orientadas a producir profundas transformaciones en las estructuras tanto político-económica como cultural-valorativa. Honneth "pone el acento en el orden de lo moral y da primacía a la integración normativa, la individualización y la inclusión social a través de diferentes esferas de reconocimiento"7 (Cifuentes, 2008, p. 125), amor, derecho y estima social. Estos autores, aunque se mantienen en el debate ${ }^{8}$, dada su adhesión a la teoría crítica, postulan un interés emancipatorio que involucra procesos socioeconómicos y políticos de amplio alcance transformativo, lo que sin duda nos compele como sociedad y nos interpela como profesión. Se trata, en todo caso, de un entendimiento de la justicia social cercano a lo político, que implicaría que sujetos y colectivos tuvieran más oportunidades de desplegar sus capacidades diversas y de participar libremente en un ámbito público democrático, en cuya construcción puedan cooperar sin que sus diferencias sean óbice para ello. En este 'libremente', es en el que cabe, más allá de lo moral, también lo ético en la noción ricoeuriana "[...] intencionalidad de la "vida buena" con y para otro, en instituciones justas". (Ricoeur, 1996, p. 176)

Teniendo en cuenta lo anterior, podemos decir que en el momento histórico actual del país el trabajo social tiene responsabilidad con el proceso de construcción de paz y esta pasa por un entendimiento de la complejidad de este y por una aproximación plural de la justicia que involucre la justicia restaurativa, la justicia redistributiva y la justicia como reconocimiento, es decir, un concepto que se aparte de los ideales de imparcialidad y universalidad postulados por el paradigma liberal dominante ${ }^{9}$. Se trata entonces de entender que la paz no se resuelve con los indispensables acuerdos gobierno-insurgencias, ni con procesos de reconciliación entre víctimas y excombatientes, esta involucra las distintas esferas de la vida social y nos compete a todos, instituciones y ciudadanos, no sólo porque la guerra se extendió de igual manera, sino porque la paz pasa por la construcción de la vida en común, en un contexto que antes que amenazarla la cultive.

\footnotetext{
${ }^{7}$ Honneth identifica las siguientes esferas de reconocimiento: amor, ley y logro. Cada una se distingue por principios normativos internos -amor, igualdad, éxito- que dan lugar a formas de reconocimiento mutuo. Este enfoque le adeuda a la perspectiva hegeliana que "entiende el reconocimiento como un proceso intersubjetivo de constitución progresiva de la identidad en el marco de sucesivas y cada vez más complejas formas de socialización: la familia, el derecho, la comunidad ética”. (Giusti, 2005).

${ }^{8}$ Young falleció en 2006.

${ }^{9}$. Apelamos aquí a las críticas de Young a estos ideales que pueden sintetizarse así:

- Sustentan la idea de Estado neutral.

- Legitiman la autoridad burocrática y los procesos jerárquicos de toma de decisiones.

- Refuerzan la opresión al transformar el punto de vista de los grupos privilegiados en posición universal.

- Enmascaran la parcialidad de la perspectiva desde la cual tiene lugar la deliberación moral.

- Generan propensión a universalizar lo particular, lo que refuerza la opresión.

- Excluyen a los grupos definidos como diferentes.

- Presuponen una racionalidad moral monológica.
} 
Trabajo social y justicia social en tiempos de transición

\section{Conclusiones}

[...] la intervención social como acto reflexivo [...] puede asentarse en cuatro vías, todas ellas complejas [...] deben analizarse de manera simultánea: la intervención como una conversación con situaciones indignas o indeseables, $[\ldots]$ con voces polifónicas, $[\ldots]$ con un contexto a modificar, [...] con la cultura. (Mosquera, 2013, p. 64)

En medio de una compleja situación que conserva características de lo que bien podría denominarse un orden de turbulencia (Gutiérrez, 1997), en el país hemos iniciado, con pasos vacilantes, lo que promete ser un azaroso camino hacia la construcción de paz.

Colombia hoy está cruzada por injusticias sociales de todo orden, las económicas, nunca resueltas y sí profundizadas y las político-culturales que han saltado a la escena pública de la mano de movimientos sociales que reivindican derechos históricamente invisibilizados. Frente al proceso de paz hay férreas y diversas oposiciones que no sólo lentifican la ejecución de los acuerdos, sino que amenazan la posibilidad de transición. El camino a recorrer está plagado de riesgos y de amenazas pero, hasta hace muy poco era impensable. Se trata de un camino que, parafraseando al poeta Machado, "se hace al andar" y habría que decir, caminando con otros diferentes. Atreverse por ese camino implica reinventarse día a día la esperanza, porque esta ha de ser compañera de la historia, no sólo la pasada, sino también la que se construye, la que abre el camino al futuro, al decir de Freire (2004) sin esta no hay historia.

Después de largos años de estudiar la guerra y de tratar con los impactos de ella en las poblaciones y en la vida social toda, ahora tenemos la enorme tarea de construir caminos hacia la paz y aprender de ese andar que no en todos los casos apenas empieza. Esa tarea compleja, arriesgada y apasionante, nos compete no sólo como ciudadanas y ciudadanos sino que interpela nuestro quehacer en investigación y acción como trabajadores sociales. La construcción de paz atraviesa todas las aristas de la vida económica, política y social colombiana y, de esta manera, involucra los diversos campos de investigación y de actuación profesional y nuestra responsabilidad ética y política.

De lo planteado en el acápite de discusión pueden derivarse asuntos claves para la producción de conocimiento y el quehacer en relación con la construcción de paz. De ellos queremos subrayar dos: de una parte, la apuesta por la construcción de ciudadanías críticas y activas, es decir, por la politización de la vida pública; de otra parte y, en relación con ello, la participación social como una participación plural y de construcción de redes de cooperación y de vínculos solidarios entorno al cuidado de lo transitado en dirección a la paz, el cumplimiento de lo ya acordado y la construcción de la vida en común. Es decir, que la participación como principio y como estrategia para la construcción de paz incumbe 
no sólo al Estado, a los excombatientes y a las víctimas, sino a toda la ciudadanía desde sus lugares diversos de interacción y actuación. Ello involucra, entre otras cosas, la participación de organizaciones de base, organizaciones defensoras de derechos humanos, grupos artísticos, instituciones sociales, familias y colectividades usualmente menospreciadas y silenciadas, que fueron especialmente golpeadas por el conflicto armado. Así, para nosotros, la participación adquiere un sentido académico, ético y político, se trata de participación en la acción, pero también, en la producción de esa "verdad más compleja" a la que aludimos anteriormente. Plantea Gadamer (2004)

[...] el modelo de diálogo puede aclarar la estructura de esta forma de participación. Porque el diálogo se caracteriza también por el hecho de no ser el individuo aislado el que conoce y afirma, el que domina una realidad, sino que esto se produce por la participación común en la verdad. (p. 313)

Ciudadanía y participación como retos para el trabajo social, en dirección a la construcción de paz con justicia social, son campos de encuentro inter y transdisciplinar, se trata de dos categorías generales y anfibias. Lo primero, en tanto son transversales a los diferentes campos de actuación. Lo segundo, retomando un concepto referido por Salvi (2017), se plantean como categorías anfibias porque se traslapan tanto en la producción académica como en el ejercicio profesional, el compromiso ciudadano y la movilización política. Es decir, son vinculadas como objeto de acción profesional, de disputa política y de investigación. Por último, pero no menos importante, se trata de campos en los que el trabajo social ha producido conocimiento, ha generado estrategias y tiene amplia trayectoria, campos interpelados por reclamos diversos de justicia social. Con este equipaje hemos de reinventarnos la esperanza para encarar los complejos retos de producción de conocimiento y acción profesional, a los que estamos abocados, retos que involucran entre muchos otros asuntos:

1. Construcción y desarrollo de pedagogías de paz que se diseminen por diferentes aristas de la vida social, acerquen a la ciudadanía al conocimiento, comprensión crítica y veeduría de cada uno de los puntos de los acuerdos - el ya establecido con las FARC/EP (2016) y el que se está negociando con el ELN-y generen corresponsabilidad con la construcción de paz. Esta tarea ha de extenderse por toda la geografía nacional, hasta los rincones más apartados de ella.

2. Procesos orientados al reconocimiento de las víctimas del conflicto armado, como ciudadanas, indispensables no sólo en la reivindicación de sus derechos, sino en la construcción de paz. Ellas no son sólo, ni principalmente víctimas, esta es una identidad atribuida para hacer parte del registro y acceder a las "medidas de reparación” (Ley 1448 de 2011). Por supuesto que es necesario que se reconozca y se repare el daño causado y 
que se les garantice el goce efectivo de derechos pero también lo es que se conozcan sus historias que no son sólo de victimización, sino también de solidaridades, de pervivencia, de resistencia, de resiliencia y de capacidad política. Aquí, el tema de la memoria ocupa lugar de singular importancia, más valdría decir, parafraseando a Jelin (2001) se trata de pensar en procesos de construcción de memorias en plural. Es fundamental acompañar a las víctimas en la apropiación ciudadana de sus derechos y en el despliegue de su capacidad de convergencia, organización y cooperación en torno a fines comunes, entre los cuales el punto del acuerdo gobierno-FARC/EP referido a las víctimas, ha de recibir especial atención.

3. Acompañamiento a los procesos de inserción social de los excombatientes, apertura de puertas a la vida civil y a la política. Ellas y ellos no llegan como los vencidos de la guerra, sino como ciudadanos a participar en la construcción de una sociedad en paz. Tienen la difícil tarea de esclarecer una verdad compleja, de asumir responsabilidad con ella, de comprometerse con la reparación a las víctimas, de reconstruir lazos de confianza y de relación en diferentes niveles, de someterse a lo establecido en la JEP, de constituirse como sujetos políticos comprometidos con su propio bienestar y con el tránsito a la paz en una sociedad aún no preparada para ello.

4. Aportar a la generación de procesos de reconciliación y convivencia que involucren no sólo a víctimas y excombatientes, sino a diversos colectivos y actores sociales sobre la base del reconocimiento mutuo, la reciprocidad y la responsabilidad en la construcción de la vida en común, como en La ciudad de las mujeres de Gioconda Belli, cultivar la cuidadanía.

5. Trabajar con enfoque territorial, multicultural y multidimensional. Identificar, debatir y afrontar en los territorios las condiciones que afectan la vida y la convivencia. Entre ellas, por ejemplo, los megaproyectos, el extractivismo, el clientelismo, el despojo y los efectos del conflicto armado.

En síntesis, se trata de reconocer la explotación material y las condiciones de opresión política y cultural a las poblaciones que afectan la calidad de la convivencia social y las opciones de hacer el tránsito social hacia condiciones de justicia social. 


\section{Un breve cierre, invitación al compromiso con la tarea académica y política de la transición}

Queremos cerrar aludiendo a Charles Dickens, quien escribe en el siglo XIX la novela "Historia de dos ciudades”. Esta inicia con una referencia a Londres y a París en el siglo XVIII, en los albores de la Revolución Francesa, aunque pareciera que Dickens habla de la Colombia actual:

Era el mejor de los tiempos, era el peor de los tiempos, la edad de la sabiduría, y también de la locura; la época de las creencias y de la incredulidad; la era de la luz y de las tinieblas; la primavera de la esperanza y el invierno de la desesperación. Todo lo poseíamos, pero no teníamos nada; caminabamos en derechura al cielo y nos extraviábamos por el camino opuesto. En una palabra, aquella época era tan parecida a la actual... (Dickens, 1859 , p. 1)

Pensar el trabajo social y la justicia social en tiempos de transición implica crear apuestas profesionales y ciudadanas que promuevan la participación social como posibilidades de encuentro, de diálogo y de movilización social alrededor de:

- La redistribución de bienes materiales, necesaria en términos de avanzar hacia una sociedad más igualitaria.

- Las demandas de reconocimiento para avanzar hacia una sociedad más plural que garantice la libertad y la igual dignidad de todos sus ciudadanos.

- El cumplimiento de lo acordado entre el gobierno nacional y las FARC/EP en términos de justicia a las víctimas, por un lado, y de condiciones y posibilidades para la reincorporación de los excombatientes a la vida civil, por el otro.

- La construcción de nuevas y diversas formas de relación orientadas a la paz como un proceso inacabado, pero también como un camino continuo que se transita paso a paso con otros, en instituciones justas.

Como diría Butler (2006) estamos ante el reto de construir una ética de la cohabitación que permita una entrada a la convivencia por un lugar distinto al de la tolerancia, un ejercicio que transforme nuestras relaciones sociales y nos permita vivir en medio de las diferencias, pero, en condiciones de igual dignidad y garantía de derechos. Un proceso en el que, como ciudadanos, nos sintamos responsables, constructores y protagonistas del florecimiento de la esperanza, como un derecho vital, que no nos podemos dejar arrebatar. Ello nos conduce a darle vida a los sueños de un país más justo, igualitario y respetuoso de las diferencias, al decir de Galeano (1996), el derecho de soñar no figura entre los 30 derechos humanos que las Naciones Unidas proclamaron a fines de 1948 pero si no fuera por él, por el derecho de soñar y por las aguas que da de beber, los demás derechos se morirían de sed. 
Trabajo social y justicia social en tiempos de transición

\section{Referencias}

Butler, J. (2006). Deshacer el género. Barcelona, España: Paidós.

Cifuentes, M.R. y Gartner, L. (2003). María Carulla de Vergara: Entre la tradición y el progreso. Manizales, Colombia: Editorial Universidad de Caldas.

Cifuentes, M.R. y Gartner, L. (2006). La primera escuela de servicio social en Colombia. Revista Trabajo Social, (8), 9-25.

Cifuentes, M.R. (2008). La justicia a las identidades colectivas, más allá del dilema distribuciónreconocimiento. Jurídicas, 5 (2), 123-138.

Dickens, C. (1859). Historia de dos ciudades. Bogotá, Colombia: Éxito Ediciones.

Foucault, M. (1992). Microfísica del poder. Madrid, España: Ediciones la Piqueta.

Fraser, N. (1997). Iustitia Interrupta. Bogotá, Colombia: Siglo del Hombre.

Fraser, N. (1998). Theorizing multiculturalism. Oxford, U.K: Cynthia Willett, Blackwell Publishers.

Fraser, N. (2001). Social Justice in the age of identity politics: redistribution, recognition and participation. Recuperado de https://tannerlectures.utah.edu/_documents/a-to-z/f/ Fraser98.pdf.

Fraser, N. (2003). Memorias del seminario internacional: Inclusión social y nuevas ciudadanías: Condiciones para la convivencia y seguridad democráticas. Bogotá, Colombia: Departamento Administrativo de Bienestar Social, serie de políticas y Pontificia Universidad Javeriana, serie política, género y democracia.

Fraser, N. y Honneth A. (2006). ¿Redistribución o reconocimiento? Madrid, España: MorataPaideia.

Freire, P. (2004). Pedagogía de la autonomía. São Paulo, Brasil: Paz e terra SA.

Gadamer, H.G. (2004). Verdad y método II. Salamanca, España: Ediciones Sígueme.

Gadamer, H.G. (2005). Verdad y método I. Salamanca, España: Ediciones Sígueme.

Galeano, E. (1996). El derecho de soñar. Diario el País. Recuperado de https:/ / elpais.com/diario/1996/12/26/opinion/851554801_850215.html

Giusti, M. (2005). Autonomía y reconocimiento. Una perdurable y fructifera controversia entre Kant y Hegel. Recuperado de http://eltalondeaquiles.pucp.edu.pe/wp-content/ uploads/2017/08/giusti-autonomia-y-reconocimiento-docx.pdf.

Gutiérrez, F. (1995). Resolución alternativa de conflictos y contexto social. Bogotá, Colombia: Ediciones Tercer Mundo. Colciencias Instituto SER Programa de Reinserción. 
Hilb, C. (s.f). Justicia, reconciliación y perdón. Recuperado de http://www.africanrhetoric.org/ pdf/08_AYOR\%203,2\%20Hilb.pdf

Jelin, E. (2001). En Los trabajos de la memoria. España: Siglo Veintiuno Editores.

Ley 1448 de 2011 (10 de junio), por la cual se dictan medidas de atención, asistencia y reparación integral a las víctimas del conflicto armado interno y se dictan otras disposiciones. Diario Oficial n. 48.096.

Maalouf, A. (2002). Identidades asesinas. Madrid, España: Alianza Editorial.

Mosquera, C. (2013). Pluralismos epistemológicos: Hacia la valoración teórica de los saberes de la acción. Una reflexión desde la intervención social a la población afrocolombiana desplazada. Bogotá, Colombia: Universidad Nacional de Colombia.

Salvi, V. (2017). Memoria social e investigación. Conferencia central presentada en el lanzamiento del Núcleo de Estudios de Memoria. Universidad Católica de Manizales. Manizales, Colombia.

Ricoeur, P. (1996). Sí mismo como otro. Recuperado de https://construcciondeidentidades. files.wordpress.com/2014/08/ricoeur-paul-si-mismo-como-otro.pdf

Uribe, M.T. (2001). Nación, ciudadano y soberano. Medellín, Colombia: Corporación Región.

Waltzer, M. (2001). Las esferas de la justicia: Una defensa al pluralismo y la igualdad. Ciudad de México, México: Fondo de Cultura Económica.

Young, I.M. (1990.). La justicia y la política de la diferencia. Madrid, España: Universidad de Valencia. Instituto de la Mujer. Ediciones Cátedra.

Young, I.M. (1998). Theorizing multiculturalism. Oxford. U.K: Blackwell Publishers

Young, I.M. (2003). Memorias del Seminario Internacional Inclusión social y nuevas ciudadanías: Condiciones para la convivencia y seguridad democráticas. Bogotá, Colombia: Departamento Administrativo de Bienestar Social, serie de políticas y Pontificia Universidad Javerina, serie política, género y democracia.

Young, I.M. (2000). La justicia y la política de la diferencia. Valencia, España: Universidad de Valencia. Ediciones Cátedra. 